\title{
Carcinogenic Habits of Tribals is It Inherited or Acquired, which Causes Oral Cavity Cancer: A Survey Report from Upper Northern Tribal Area of Andhra Pradesh (India)
}

\author{
Naik Balachandra Ramachandra \\ Assistant Professor, Department of Pathology, Mamata Medical College, Khammam, Andhra Pradesh, India
}

Correspondence: Naik Balachandra Ramachandra, No. 85, Madhura Chetana Colony, Kusugal Road, Hubli-580023, Karnataka India, Phone: 09985538541, e-mail: drnbr.57@gmail.com

\begin{abstract}
Khammam is the district of tribals in the Andhra Pradesh (India). Recently, we have conducted a study on oral cavity cancer in this tribal area and found that the incidence of oral cancer was $13.04 \%$, male to female ratio was $1.03: 1$ and the incidence of oral cancer in youths (between 21 and 30 years) was $4.85 \%$, which was too much compared with the global previous studies.

So, we decided to find the cause for the high incidences of oral cavity cancer among the youths, by conducting survey and by direct interviewing the youths at their villages and at their towns separately for the comparison between both locality youths. Also we undertook clinical examination of their oral cavity to find the presence of any pathological lesions. We prepared the proformas well in advance containing various parameters which cause oral cavity cancer and conducted mass interview of 3,000 youths both at rural and urban places separately. Master chart of both places was prepared and compared the differences between these two localities, to find the cause for increase in incidences oral cavity cancer. In rural area, out of 3,000 youths, 2,907 (96.9\%) (including 1,605 male and 1,302 females) had various combination of habits whereas, in urban area, among 3,000 male youths, only $953(31.76 \%)$ had various combination of habits. Illiteracy status in rural area was $77.56 \%$ and in the urban area, it is $13.23 \%$. Among the youths having habits, various types of chewing habits in rural area were seen in 2,722 (93.69\%) youths. In urban area, it was seen in 934 (98\%). Among all 3,000 youths of each locality, oral cavity hygiene was unhygienic in $2,387(79.56 \%)$ youths of the rural area whereas, in the urban area it is seen in $1109(36.96 \%)$. Premalignant changes were seen 21 rural youths, but not in urban residents.

Education has vital role in rural area to control the chewing habits, for which media role and legislative act to ban the tobacco chewing should be mandatory to reduce the incidence of oral cavity cancer among the youths of tribal villages.

Keywords: Educate tribal youths, reduce incidence of oral cavity cancer to equalize with western countries, stop smoking, chewing and alcohol habits.
\end{abstract}

\section{INTRODUCTION}

There are 1,200 million smokers and hundreds of millions of smokeless tobacco users in the world, ${ }^{1,2}$ a huge amount of tobacco is consumed worldwide in the form of smokeless tobacco products, ${ }^{3}$ including chewing tobacco which is placed between the cheek and gum for longer duration. Pan is the quid, which constitutes betel nut, lime, flavoring substances and also may contain tobacco, which is more common in India.

These chewing (smokeless) tobaccos are called by different names like chewing tobacco, moist snuff, pan/ betelquid and gutkha in India. ${ }^{2}$ People smoke tobacco in the form of kreteks, sticks, bidies, cigars and cigarettes. ${ }^{1}$

Smoking is the cause for the cancer of various organs of the human beings, including oropharyngial cancers. ${ }^{4}$
Tobacco smoke contains 62 carcinogens, of these 15 carcinogens cause oral cavity cancer, ${ }^{2,5}$ for example, cigarettes smoke.

Contains carcinogens like polycyclic aromatic hydrocarbons (PAH), N-nitrosamines, aromatic amines, benzene, aldehydes and ethylene oxide. ${ }^{5}$ There is sufficient evidence that in India, smokeless tobacco causes oral cavity cancer. ${ }^{6}$ Smokeless tobacco contains strong carcinogens like N-nitrosonornicotine (NNN) and 4-(methylnitrosamine)-1(3-pyridyl)-1-butane (NNK). ${ }^{5}$ Betel leaves and betel nut (areca nut) are also carcinogenic. ${ }^{7}$ Now, it proved that alcohol is too carcinogenic. ${ }^{8}$

Oral cancer incidences and mortality shows major world wide differences, but the highest rate of oral cancers is registered in India and neighboring countries. ${ }^{9}$ 
Oral cancer is the one of the few cancers, whose cause is known and hence, it is possible to prevent it. The real challenge in oral cancer lies in its prevention and early diagnosis ${ }^{10}$ hence, the present study is taken to find the cause for rise in the incidences of oral cavity cancers among the tribal youths and motivated them to give-up these habits.

\section{MATERIAL AND METHODS}

I took the help of three local technicians (including one female technician) for motivating, getting cooperation of youths and conversation in regional language and to conduct clinical examination of oral cavity to complete our required parameters.

The aim of present study was to consider the youths (between 11 and 30 years) of rural and urban separately, randomly selected 3,000 youths from each localities one after other areas. First we went to villages, one by one to complete our target of selecting 3,000 youths for the interview and clinical examination of their oral cavity, to complete our goal at villages, we took 17 days continuously and visited 17 villages after 4 pm (as majority of youths are out of their village for their livelihood work and returns back by $4 \mathrm{pm}$ onwards), we have included females of the above age groups here, because they also have various habits equally with males. All the parameters required for us were entered in the proformas separately for each youth. Later, we selected three urban (town places including Khammam) areas and met to the youths at railway station, bus stands and in the market places, where more population movement is present. We have excluded females because they do not have habits which cause oral cavity cancer. The detailed face-to-face interview was entered in the proformas, including oral cavity clinical examination and finally made the master charts of both regions separately, for comparison and coming to the conclusion.

\section{RESULTS}

In rural area, 3,000 (1,666 males and 1,334 females) youths were interviewed by us, of these 2,907 (1,605 were male and 1,302 were females) had various combination of habits, forming male to female ratio $1.2: 1$. Chewing habit was most common habit seen in 2,805 (96.49\%) youths, constituting males 1,522 (94.82\%) and females 1,283 (98.54\%) (Table 1 and Fig. 1). 922 youths (57.44\%) enjoyed their chewing habit for the period of 6 to 15 years whereas, 725 (55.68\%) females had the habit of chewing for the period of 10 to 20 years.

Among 3,000 youths, $77.56 \%$ do not have the knowledge of writing and reading. Clinical examination of oral cavity found that (Table 3), the oral cavity hygiene was unhygienic in 2,387 (79.56\%) (Table 2 and Fig. 2) and in $21(0.72 \%)$ youths constituting $13(0.8 \%)$ males and 9 (0.69\%) females premalignant changes in the buccal mucosa was found, we have advised them to stop habits immediately and explained the future consequences to them. Their diet was mixed and rarely they eat fruits.

Among, 3,000 male youths at three town places, only $953(31.76 \%)$ had various combination of habits, which causes oral cavity cancer of these, 944 (99.05\%) youths had mainly gutkha and tobacco chewing habits (Table 4) and

Table 1: Various habits and percentage of habits in tribal rural

\begin{tabular}{|c|c|c|c|c|c|}
\hline SI. no & Habits & Male & Female & Total & Percentage \\
\hline 1. & Betel leaves + Betel nut + Lime-chewing & 113 & 98 & 211 & 7.25 \\
\hline 2. & Tobacco + Lime-chewing & 97 & 78 & 175 & 6.03 \\
\hline 3. & Gutkha-chewing & 3 & Nil & 3 & 0.1 \\
\hline 4. & Betel leaves + Betel nut + Lime + Tobacco-chewing & 465 & 493 & 958 & 32.95 \\
\hline 5. & Betel leaves + Betel nut + Lime + Gutkha-chewing & Nil & Nil & Nil & Nil \\
\hline 6. & Alcohol + Smoking & 83 & 19 & 102 & 3.5 \\
\hline 7. & Alcohol + Tobacco-chewing & 151 & 129 & 280 & 9.63 \\
\hline 8. & Alcohol + Gutkha-chewing & Nil & Nil & Nil & Nil \\
\hline 9. & Betel leaves + Betel nut + Lime + Tobacco-chewing and alcohol & 403 & 337 & 740 & 25.45 \\
\hline 10. & Betel leaves + Betel nut + Lime + Gutkha-chewing and alcohol & Nil & Nil & Nil & Nil \\
\hline 11. & Betel nut + Betel nut + Lime-chewing and alcohol & 7 & 13 & 20 & 0.68 \\
\hline 12. & Betel leaves + Betel nut + Lime-chewing and smoking & 74 & 25 & 99 & 3.4 \\
\hline 13. & Betel leaves + Betel nut + Lime + Tobacco-chewing and smoking & 193 & 91 & 284 & 9.76 \\
\hline \multirow[t]{2}{*}{14.} & Betel leaves + Betel nut + Lime-chewing along with smoking and alcohol & 16 & 19 & 35 & 1.2 \\
\hline & Total & 1605 & 1302 & 2907 & 100 \\
\hline
\end{tabular}




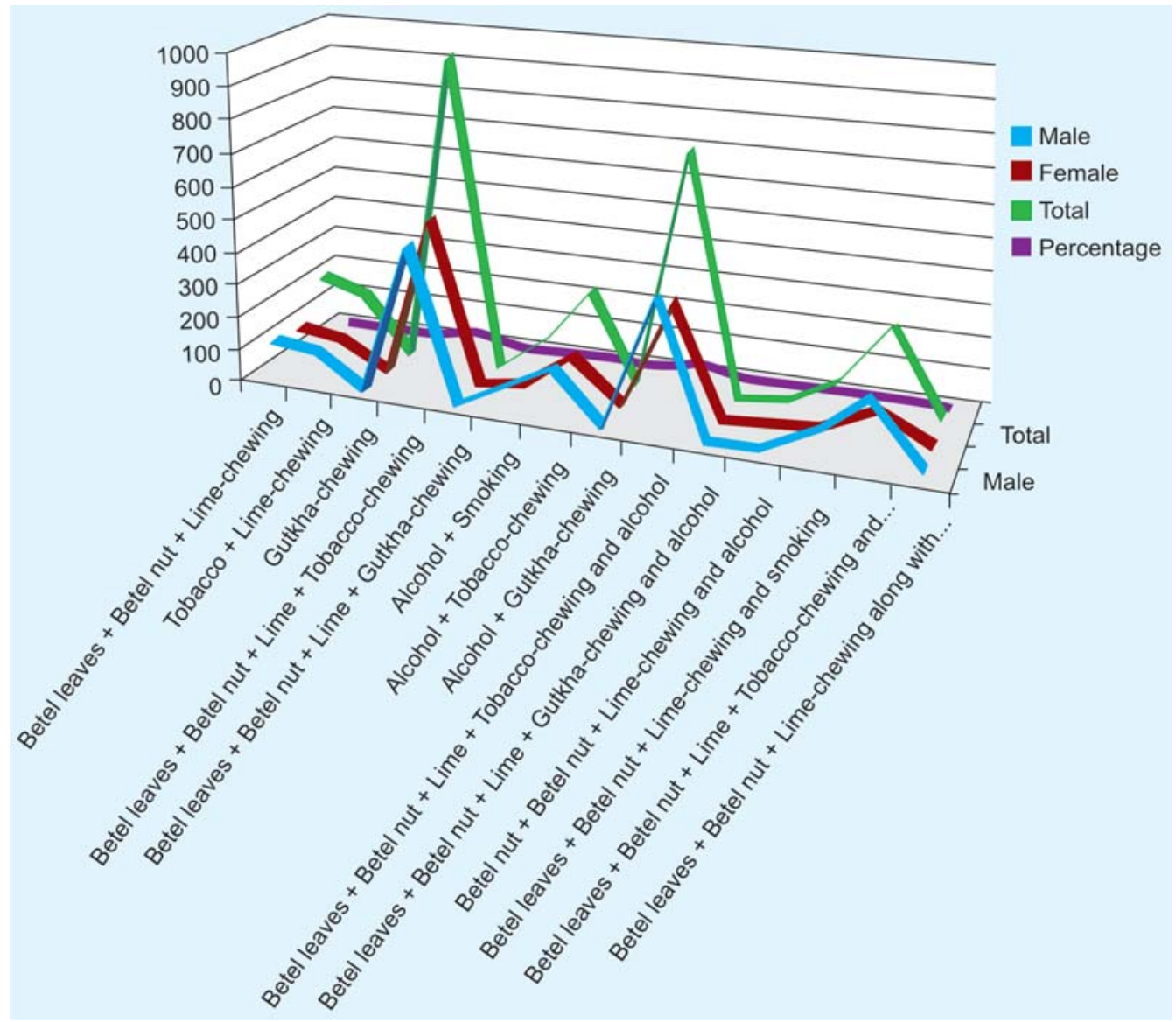

Fig. 1: The graph showing various habits among the youths of rural area

Table 2: Oral cavity hygienic and unhygienic status in urban and rural tribals

\begin{tabular}{lclll|} 
& Hygienic & $\begin{array}{l}\text { Hygienic } \\
\text { total \% }\end{array}$ & Unhygienic & $\begin{array}{l}\text { Unhygienic } \\
\text { total \% }\end{array}$ \\
\hline Rural & 613 & 20.43 & 2,387 & 79.56 \\
Urban & 1891 & 63.03 & 1,109 & 36.96
\end{tabular}

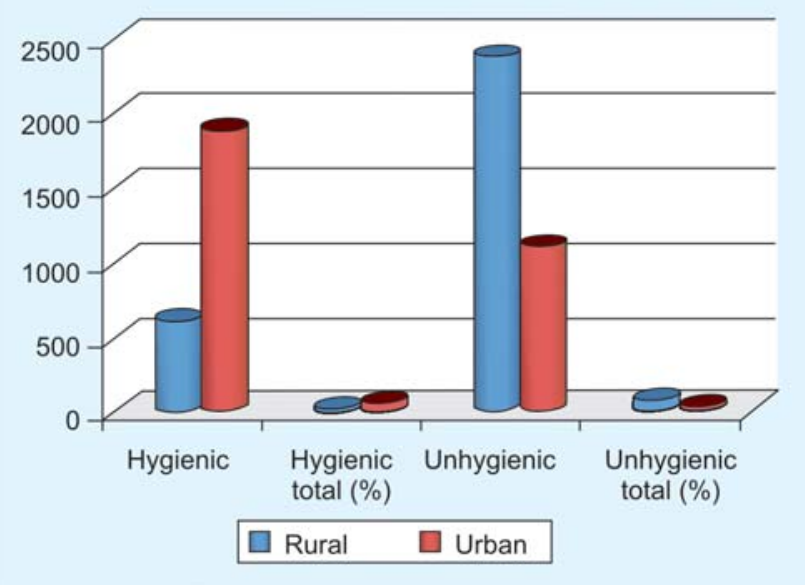

Fig. 2: The comparison of oral hygiene among rural and urban youths
Table 3: Education status in rural area of tribals

$\begin{array}{lrrrc}\text { Education status } & \text { Male } & \text { Female } & \text { Total } & \text { Percentage } \\ \text { 1. Uneducated } & 1081 & 1246 & 2327 & 77.56 \\ \text { 2. Up to primary school } & 511 & 81 & 592 & 19.73 \\ \text { 3. Up to high school } & 71 & 7 & 78 & 2.6 \\ \text { 4. Up to college } & 3 & \text { Nil } & 3 & 0.1\end{array}$

2,606 youths enjoyed the chewing habit for the period of five years. 2,603 (86.76\%) youths had reading and writing knowledge (Table 5). Clinical examination of oral cavity revealed that 1,109 (36.96\%) of youths do not have hygienic oral cavity (Table 2 and Fig. 2) and premalignant lesions of oral cavity were not found in them. Majority of them preferred mixed diet, they routinely eat vegetables and fruits.

\section{DISCUSSION}

Oral cavity cancer is the sixth most common cancer and the major cause for morbidity and mortality. Annually, around 50,000 oral cancers are diagnosed throughout the world of these; three quarters are from the developing countries. ${ }^{11}$ Indian low income group people are uneducated; 
Table 4: 782 (82.05\%) urban youths chewed gutkha

\begin{tabular}{|c|c|c|}
\hline Sl. no & Habits & Urban male \\
\hline 1. & Betel leaves + Betel nut + Lime-chewing & 19 \\
\hline 2. & Tobacco + Lime-chewing & 83 \\
\hline 3. & Gutkha-chewing & 407 \\
\hline 4. & Betel leaves + Betel nut + Lime + Tobacco-chewing & 18 \\
\hline 5. & Betel leaves + Betel nut + Lime + Gutkha-chewing & 91 \\
\hline 6. & Alcohol + Smoking & 9 \\
\hline 7. & Alcohol + Tobacco-chewing & 5 \\
\hline 8. & Alcohol + Gutkha-chewing & 173 \\
\hline 9. & Betel leaves + Betel nut + Lime + Tobacco-chewing and alcohol & 3 \\
\hline 10. & Betel leaves + Betel nut + Lime + Gutkha-chewing and alcohol & 111 \\
\hline 11. & Betel nut + Betel nut + Lime-chewing and alcohol & Nil \\
\hline 12. & Betel leaves + Betel nut + Lime-chewing and smoking & 2 \\
\hline 13. & Betel leaves + Betel nut + Lime + Tobacco-chewing and smoking & 13 \\
\hline \multirow[t]{2}{*}{14.} & Betel leaves + Betel nut + Lime-chewing along with smoking and alcohol & 19 \\
\hline & Total & 953 \\
\hline
\end{tabular}

they usually chew tobacco, smoke bidies and drink alcohol. Majority have poor oral hygiene. They eat less vegetables and fruits. ${ }^{12}$ Smokers have higher death rate due to oral cancers as well as other types of cancers elsewhere in the human compared to nonsmokers. ${ }^{13}$ Nowadays, there is increase in the incidence of oral cancer in youths, the reason for this is smokeless tobacco called as gutkha, which targeted youths. Now, gutkha has become extremely popular among youths. ${ }^{14}$

Gopalkrishna et al (1967) study says, youths between 21 and 30 years of age got 3.15\% of oral cancer. ${ }^{15}$ Our recent study at this tribals area also found that the youths, between 21 and 30 years of their age, got oral cancer more than the above studies, that is, the incidence of oral cancer in youths is $4.85 \%$. Increase in incidence of oral cancer in youths may be due to adopting chewing habits at early age.

R Shankarnarayana et al (1989) study on oral cancer in South India says that in India, sex incidence varies from state to state. ${ }^{16}$ In this tribal area, male to female ratio is $1.03: 1$, which was almost equal in both sexes. The reason for this was, both male and female were equally having habit of chewing, smoking and alcohol.

WHO Atlas 2003 says that tobacco use estimated to have killed 100 million people in the 20th century and is expected to claim the lives of ten times of that number, one billion in this century based on the current trend. The burden of death and disease caused by tobacco is shifting rapidly to low income nations, as the most high income nations are implementing effective tobacco control policies. ${ }^{17}$ Tobacco is very significant risk factor in causation of oral cancer, the risk increases further, when combined with alcohol. The
Table 5: Education status in urban area of tribals

$\begin{array}{lrrc}\text { Education status } & \text { Male } & \text { Total } & \text { Percentage } \\ \text { 1. Uneducated } & 397 & 397 & 13.23 \\ \text { 2. Up to primary school } & 605 & 605 & 20.16 \\ \text { 3. Up to high school } & 1167 & 1167 & 38.9 \\ \text { 4. Up to college } & 831 & 831 & 27.7\end{array}$

quantity and duration of their consumption are also important factors in causing oral cavity cancer. ${ }^{18}$

Gopalkrishna et al (1967) found that $80.4 \%$ were tobacco chewer and $51.5 \%$ were smokers. ${ }^{15}$ Khanna NN et al (1975) found that $80.46 \%$ were tobacco chewer, $31 \%$ were smokers. ${ }^{19}$ Our recent study found that along with various combination of habits, tobacco-chewing habit was seen in 276 (89.96\%) patients, alcoholics were 274 (88.67\%) and smoking habit was seen in 139 (44.98\%) patients.

Smokeless tobacco are used in the form of tobacco quid, which is kept in between the gum and buccal mucosa for longer duration. ${ }^{20,21}$ At teenage, most of people start smoking and become addicted to nicotine then onward smoke habitually. Nicotine is not an carcinogenic but it is accompanied by mixer of carcinogens which are responsible for oral cavity and other organs cancer. ${ }^{21,22}$

Pankaj Chaturvedi (2010), clearly mentioned that, betel nut in India is chewed alone or as a betel quid (pan) in combination with tobacco, lime and other spicy flavoring agents. Betel nut is classified as Group I human carcinogen and is the cause for the precancerous condition (submucus fibrosis) and cancer of the oral cavity, if it is consumed. It gives synergistic carcinogenic effect, if it is chewed along with tobacco. Betel leaves too contain carcinogen, which is called as Safrole. ${ }^{8}$ 
Alcohol consumption along with smoking greatly increases the risk of oral cavity cancer. ${ }^{4}$ If we open the internet with these words, "Alcohol and cancer" we get sufficient materials, which say that alcohol is carcinogenic.

Government and various organisations have spent billions of rupees in the past to control tobacco use. ${ }^{8}$ It is better to go through tobacco carcinogen biomarker, which helps ultimately to evaluate new tobacco products and also it has potential as it measures individual susceptibility to the effect of cigarette smoke. ${ }^{23}$

In the year 2008 on 2nd October, Government of India passed a Legislative Act to ban smoking in public places, but this message not yet reached to the tribals of this region. It is very difficult to predict that, whether these youths will give up the above habits or not and in future will we see the reduced incidences of oral cancer? Because, the father of Psychoanalysis by the name Sigmund Freud started smoking at the age of 24, he refused the advice of his physician. At the age of 72, he got palate cancer and wrote about his fatal habit, for me it is very difficult to give up smoking habit as it gives pleasure to me. He died due to palate cancer in the year $1939 .^{24}$

\section{CONCLUSION}

Cigarette/ bedies smoking and chewing habit is clearly the greatest preventable cause of oral cavity and other organs cancer because of addictive power of nicotine, though it is noncarcinogenic, but it carries various carcinogens. Smokeless tobacco is widely used by the youths, which is kept for longer period in between the gum and cheek, which makes the oral mucosa to get irritated and thus results in oral cavity cancer. Now, it is badly needed to ban the sale and chewing the smokeless tobacco (gutkha) in public places, if not followed this ban order by users then increase taxation to the user is must and aggressive antitobacco advertization is needed; for this media role is very much essential. In western countries, their country Legislative Act reduced consumption of tobacco products and thus incidence of oral cavity cancer reduced because people are educated and they respect to their country law. We need the same to reduce incidences of oral cavity cancer in tribals, for this Government and other social organization role is essential otherwise, incidence of oral cavity cancer is tribal area will retain its highest position in the world.

\section{ACKNOWLEDGMENT}

I am grateful to the tribal youths and three technicians for their cooperation and motivation to respond our interview and clinical examination of oral cavity as, I have utilized them to bring the facts for the cause of oral cavity cancer in tribals of this area.

\section{REFERENCES}

1. Mackay J, Eriksen M. The tobacco atlas. World Health Organization, Geneva 2002;24.

2. International Agency for Research on Cancer. Tobacco smoke and involuntary smoking. IARC Monographs on the Evaluation of Carcinogenic Risk to Humans, Lyon, IARC, France 2004;83:53.

3. International Agency for Research on Cancer. Tobacco smoke and involuntary smoking. IARC Monographs on the Evaluation of Carcinogenic Risk to Humans, Lyon, IARC, France 2004;83:1179.

4. International Agency for Research on Cancer. Smokeless tobacco and tobacco specific nitrosamines. IARC Monographs on the Evaluation of Carcinogenic Risk to Humans, Lyon, IARC, France 2007;89.

5. International Agency for Research on Cancer. Tobacco smoking. IARC Monographs on the Evaluation of Carcinogenic Risk of chemicals to Humans, Lyon, IARC: France 1986;38:37.

6. Zain, et al. J Oral Pathol Med 1999;28:1-4.

7. Chaturvedi Pankaj. International Journal of Head and Neck Surgery, January-April 2010;1:17-20.

8. www.alcohol and cancer.

9. Carlo La Vecchia. Oral cancer, epidemiology, risk factors, prevention, screening, intervention oral oncology, Proceedings of the 5th International Congress on oral cancer, 1997;5:5-10.

10. AD Singh. Challenge of Oral Cancer in India. Indian J of Radiology 1981;35(3):147-55.

11. Jatin K, Nagapal, Bibhu R. Oral cancer: Reviewing the present understanding of its molecular mechanism and exploring the future directions for its effective management. Oral oncology 2003;39:213-21.

12. I Hindle, MC Downer, PM Speight. The epidemiology of oral cancer. British Journal of Oral and Maxillofacial Surgery 1996;34:471-76.

13. Prakash C Gupta, Fali S Mehta, RR Irani. Comparison of mortality rates among bidi smokers and tobacco chewers. Indian Journal of Cancer 1980;17:149-52.

14. Prakash C Gupta. Tobacco and youth in the South-East Asian Region. Indian Journal of Cancer 2002;5-29.

15. Gopal Krishna, ON Saxena, AK Singh. Oral Carcinoma. Indian Journal of Surgery 1967;229-35.

16. R Sankaranarayan, et al. A case control investigation of cancer of the oral tongue and the floor of the mouth in Southern India. Journal of Cancer 1989;44:617-21.

17. Cancer Forum. Historic global tobacco control treaty welcomed and now the real work begins. 2003;27(2):121-25.

18. PK Varshney, N Agrawal, LM Bariar. Tobacco and alcohol consumption in relation to oral cancer. Indian Journal of Otolaryngology and Head and Neck Surg 2003;55:25-28.

19. Khanna NN, et al. Some observations on the etiology of oral Cancer. Indian Journal of Cancer 1975;1:77-82. 
20. Condict More, et al. Anatomic Origins and Locations of Oral Cancer. American J of Cancer 1967;510-13.

21. Guengerich FP. Common and uncommon cytochrome P450 reactions related to metabolism and chemical toxicity, chemical Res Toxicol 2001;14:611.

22. Jalas J, Hecht SS, Murphy SE. Cytochrome 450 2A enzymes as catalyst of metabolism of 4 (methyl nitrosamino)- 1-(3-pyridyl)- 1-butanone (NNK), a tobacco specific carcinogen. Chem Res Toxicol 2005;18:95.

23. Hatsukami DK, Benowitz NL, Rennard SI, et al. Biomarkers to assess the utility of potential reduced exposure tobacco products. Nicotine Tab Res 2006;8:169.

24. Nicholas Lazaridis, Historical note, Sigmund Freud's oral cancer. British Journal of Oral and Maxillofacial Surgery 2003;41:78-83. 